\title{
Industry Driven Curriculum Development, the Key to Successful Courseware
}

\author{
Jerome Tapper \\ Northeastern University, School of Engineering Technology
}

\begin{abstract}
Designing a curriculum of courses based upon donated equipment can be made easier if the donors help with this task. Not only are equipment manufacturers the best sources for gaining donated state of the art equipment, but they can also be an important resource when it comes time to develop the actual course material and content needed for new courses involving the use and application of their equipment and products. Northeastern University's School of Engineering Technology has been fortunate to have received substantial laboratory equipment donations from major players in the Industrial Control Systems industry. These same players have generously contributed supplemental training materials in addition to their own time to assist in developing course curriculum for our program. This paper addresses the construction of this new curriculum and in particular the part industry has played. The results of a pilot courseprogram conducted in the Fall of 1999 are included along with comments from participating students.
\end{abstract}

\section{Background}

For the past two years, the author has been engaged in establishing industrial partnerships whose goal is to create strong ties to the industrial base in the Boston and surrounding New England areas. The impetus for creating these strong ties is linked to this educator's desire to improve future student cooperative work assignments, and increase both after-graduation employment opportunities and industrial research project assignments. Over the past two years, industrial partnerships have been established with two leaders in the industrial control systems market, Siemens Energy and Automation Corporation and Cutler-Hammer Corporation. ${ }^{23}$ Partnerships have been established with several other smaller players as well. Each of these companies has committed itself to assisting Northeastern University's School of Engineering Technology in achieving its goal of becoming a prominent provider of quality Industrial Control Systems (ICS) training. To this end, these companies have made substantial equipment donations to our program. Working closely with corporate donors has allowed our newly developed industrial control systems courses to become greatly enriched by virtue of "working with the masters" themselves. The following describes the courses that were developed and implemented under the creative and watchful eye of our industrial partners.

Proceedings of the 2001 American Society for Engineering Education Annual Conference \& Exposition Copyright (C) 2001, American Society for Engineering Education 


\section{Product Knowledge - The First Hurdle}

In order to properly "teach" a curriculum that can be considered new and innovative, it is necessary for the instructor to completely understand how the donated products operate. Without this understanding, the curriculum will be both incomplete and underdeveloped, a result that will be counterproductive for students and donors alike. A lack of understanding on the part of the curriculum designer can have significant negative effects on the outcome of the program. Introducing a piece of equipment that the instructor is not completely familiar with may result in student's loss of confidence in the instructor and the curriculum as a whole. Remember, the students themselves are the "best" promoters (or detractors) of any course and a new course can live or die on this premise. Therefore - know thy products well.

\section{Training the Trainer - The Way To Do It Right}

To gain a better understanding of donated equipment, an instructor can opt for product knowledge training directly from the source - the manufacturer. Many, if not all product manufacturers provide in-house or distributor based in-house product training. Accessing Original Equipment Manufacturer's (OEM) training is highly recommended and offers the following advantages:

- The opportunity to be trained by the so-called masters themselves. After all, being trained by the folks that created the product is far better then being trained by second or third hand parties. Here, good training techniques can be garnered along with methods to determine how to order and what material to emphasize.

- Exposure to the most current technology on the market. OEM training is always focused on teaching the latest state-of-the-art products that companies have to offer.

- The possibility of free tuition. Companies which have donated equipment to an educational program will usually allow program facilitators to attend OEM training courses tuition free. Note that not all OEMs will waive tuition fees, - the ones most likely to do this are those who have the most to gain by supporting your program.

Keep in mind that the equipment manufacturer has a vested interest in training how to properly teach equipment theory and application to as many people as possible. It is suggested that comprehensive notes be taken and as much educational/training material be collected during this training session in order to facilitate future course/curriculum development.

\section{DESIGNING A FIRST INDUSTRIAL CONTROL SYSTEMS COURSE}

Once you have an understanding of how to properly use each piece of equipment, the curriculum developer must develop course material, determine the order of presentation, and select an appropriate title. ${ }^{1}$ 
The advice offered from the manufacturers themselves was one of the most important influences to this author's curriculum development. Many industry experts such as corporate trainers field applications engineers, sales representatives etc. were consulted for their opinions regarding appropriate curriculum. All played a very important role in helping shape course material.

\section{The Lecture-Lab Experience}

One of the major decisions made was to design the new course/curriculum using a combination "lecture-laboratory" venue. Prior to this, lecture and laboratory courses given at the School of Engineering Technology and Northeastern University were independent of each other. For example, a theory lecture was an independent "stand-alone" course separate from its counterpart laboratory meeting. The idea behind a combined lecture-laboratory was to give the students a real-time look and feel for what they were being taught. There was consensus from the industrial advisors and this author that this approach would be most effective, as by definition "Engineering Technology" is a truly "hands-on" applied curriculum.

In creating this new teaching venue, one of the most important elements to consider was the amount of (in class) time available for teaching a new and ambitious course. After all, there is only a limited amount of time that can be spent in any given course. Northeastern University's School of Engineering Technology is on the quarter system, with approximately 10 weeks per quarter. A typical $4 \mathrm{QH}$ course lasts about 3 hours per week, a possible serious time constraint for a "new venue" such as the one presented here.

\section{INDUSTRY INFLUENCE}

\section{Order of Course Material Presentation}

As with all well developed courses the order of material presentation is key, and this course was no exception. At the suggestion of the course's industrial advisors, the following topical order was established:

- A Brief History of Industrial Control Systems

- Safety in the Industrial Control Systems Environment

- Limit Switches

- Proximity Sensors

- Photoelectric Sensors

- Basics of Programmable Logic Controllers (PLC)

- Basics of AC Motors

- Basics of AC Variable Frequency Drives

In addition to these topics, students were required to perform weekly design applications.

Proceedings of the 2001 American Society for Engineering Education Annual Conference \& Exposition

Copyright (C) 2001, American Society for Engineering Education 


\section{COURSE MATERIAL CONTENT}

As mentioned previously, the content of this course was greatly influenced by the industrial advisors, namely the donor OEMs. The topics selected were chosen to allow the student the greatest exposure to the largest amount of equipment possible without sacrificing theoretical understanding. After all, it does no good to expose a student to something that he/she cannot apply or understand when in the field. Moreover, a comprehensive understanding of a few devices is far better than a superficial understanding of many. The following is a brief overview of the material content developed for this course.

- A Brief History of Industrial Control Systems

It was the unanimous sentiment among advisors that some historical perspective should be presented as part of this course, as students can only appreciate current technologies if made aware of previously applied techniques. The historical context of the need for industrial control systems was introduced, along with videos showing actual industrial field ICS applications.

\section{- Safety in the Industrial Control Systems Environment}

It was again the unanimous feeling that the topic of "safety" should be incorporated into the course materials. Safety is a big issue in the industrial control systems environment as accidents causing serious injury or death could occur if the ICS engineer is not careful or knowledgeable of the possibilities for danger.

\section{- Limit Switches, Proximity Sensors, Photo-electric Sensors}

In order of complexity, the most basic elements in an industrial control system are the "Limit Switch", "Proximity Sensor", and "Photo-electric Sensor". Each are capable of indicating various conditions of a system such as "on or off", "open or closed", etc.. Because these are the most basic ICS elements, they became the first technical topics of this author's course.

Industrial equipment manufacturers have assisted in disseminating information about limit switches, proximity sensors and photo-electric sensors. The component manufacturers (OEMs) can and have played a major role in helping to develop the material needed for course curriculum about these topics. For example, sensor catalogs, such as that shown in Figure 1 from CutlerHammer Corporation, not only contain component part numbers and specifications, but also "indepth" technical explanations of the theory and operation of each limit switch and sensor type used in this course. The techniques used to explain and demonstrate these devices was left to the instructor.

Technical hand-outs of information contained within these catalogs was used. Keep in mind that although copyrighted, most manufacturers will not mind if you copy these application pages as long as their name and logo are included. After all, these catalogs are usually provided to customers and any interested parties for sales purposes.

Proceedings of the 2001 American Society for Engineering Education Annual Conference \& Exposition Copyright () 2001, American Society for Engineering Education 


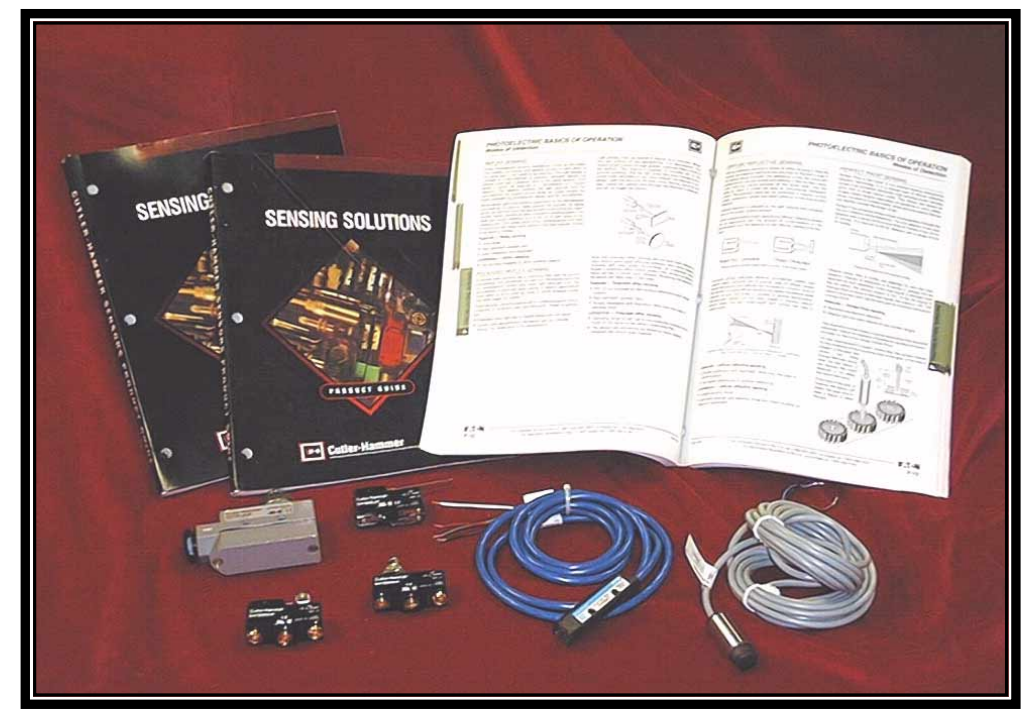

FIGURE 1 Cutler-Hammer Sensor Catalog

It is important to understand that many ICS companies manufacture components and develop similar catalogs containing switch information to those mentioned here. It really does not matter which vendor's catalog you use in a given ICS course since all of these switch devices technically operate on the same principles. It is recommended for obvious reasons that you use the catalogs of those manufacturers who actually donated your equipment. Incidentally, it is worth noting that it does make a difference if the students can "use" and "operate" the actual equipment that they see in a catalog. This seems to give them a sense of closure to the learning process.

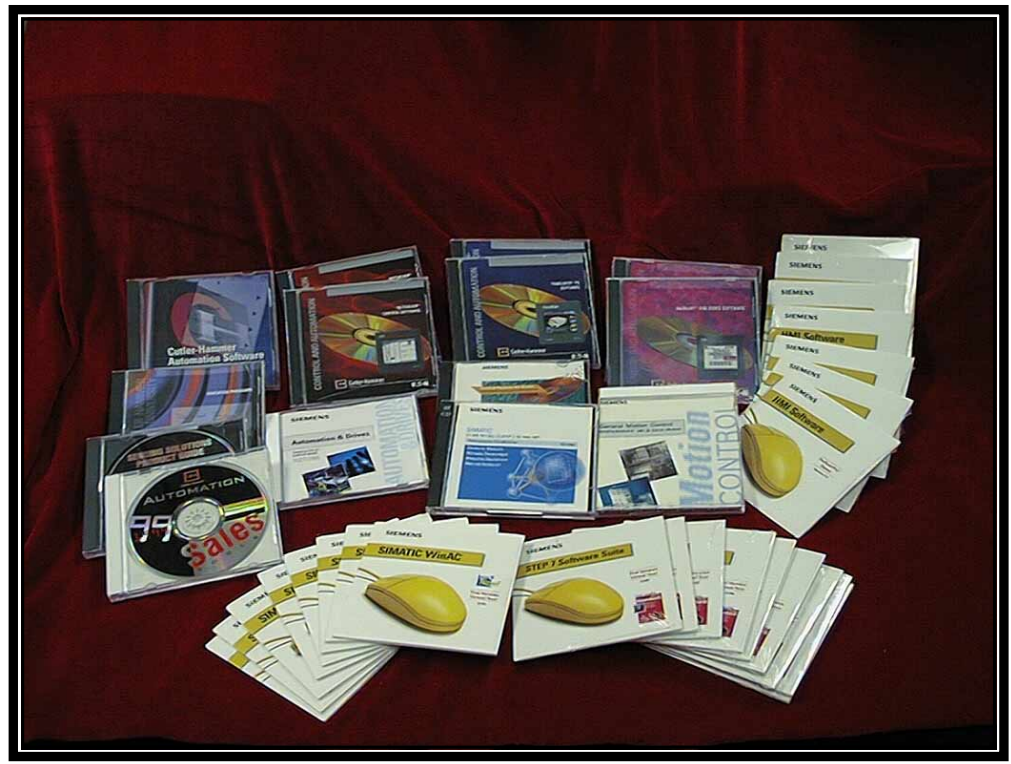

FIGURE 2 Assorted Promotional CDs Used for ICS Class Discussion

Proceedings of the 2001 American Society for Engineering Education Annual Conference \& Exposition Copyright @ 2001, American Society for Engineering Education 
To assist the course developer, industrial manufacturer supplied materials can be used to provide a clearer picture of the industrial control systems environment. Most if not all of these equipment manufacturers have compact discs (CD) that they use for sales/marketing and seminar purposes. (Several of these can be seen in Figure 2.) Their value in an ICS course lies in their providing invaluable information on technical product comparisons and market trends. Don't be fooled because they are marketing and sales tools - they can be very valuable if applied correctly in the class room.

\section{- Basics of Programmable Logic Controllers (PLC)}

Once the ICS "input" devices such as the Limit Switches, Proximity Switches and Photo-electric Switches are explored, the "main" ICS decision making device, the Programmable Logic Controller (PLC), must follow. Clearly the most popular of all the ICS devices, the Programmable Logic Controller contains the brains of the ICS system and is widely accepted as the defacto standard in ICS control. Similar to the PLC of years gone by, the PLC of today boasts of a more powerful processor, faster response time, more powerful instruction set, and most importantly - it is easily networkable.

Material presented in an ICS course must explain the hardware as well as the software in depth, as they are mutually dependent. PLC controllers utilized in this course were Micro PLCs from Siemens Corporation, examples of which can be seen in Figure 3 below.

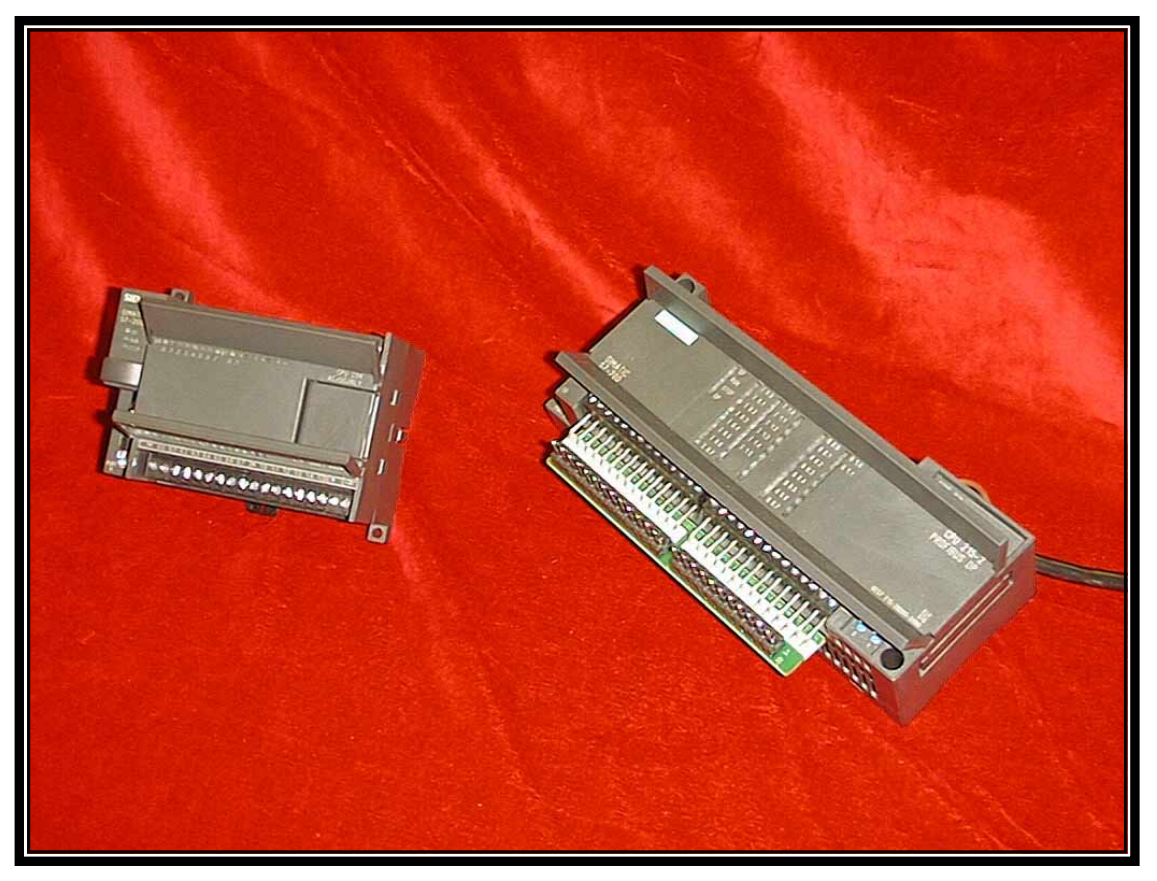

FIGURE 3 Siemens Micro Programmable Logic Controllers Used in ICS-1 
Again, the best way for an instructor or curriculum developer to gain knowledge of these devices is to attend OEM provided training seminars or school as outlined in the "Training the Trainer" section of this paper. Most larger PLC manufacturers have a very diversified product line and therefor provide many different product oriented training schools. These schools can vary from a one-day seminar to a full blown 5 day course. Be selective and start with the basics as training course content can get quite complex and over-powering very quickly.

What makes PLCs interesting is that they(multi-vendor manufactured) are all very similar in operation. Learning any one of these will allow the developer to quickly understand the concepts behind other manufacturer's products.

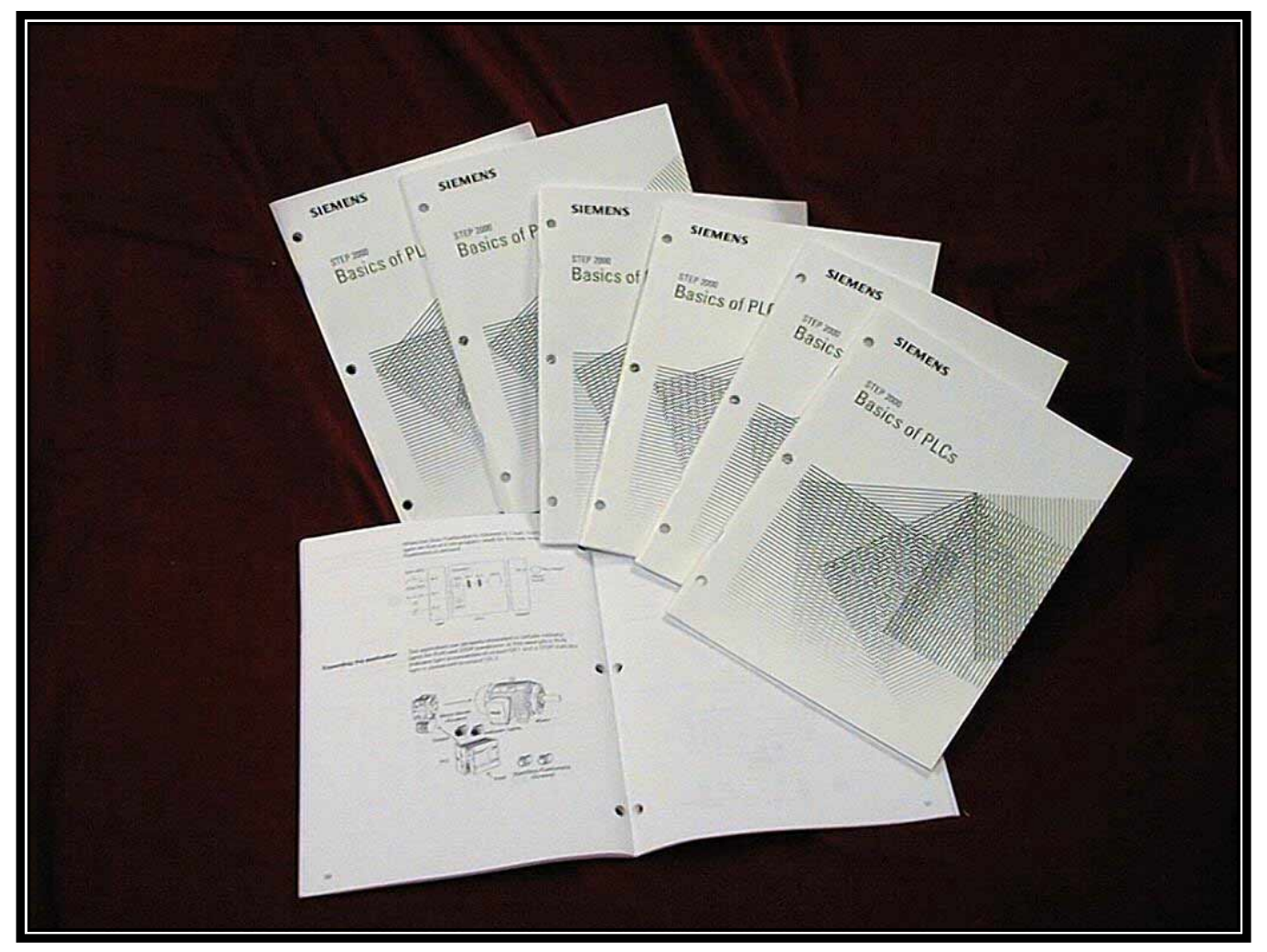

FIGURE 4 Siemens Corporation “Step 2000 - Basics of PLC” Manuals

In addition to providing CDs and other training course materials, our industrial donor, Siemens Corporation also donated several hundred 100+ page soft cover books titled Basics of PLSs. Examples of these can be seen in Figure 4. Siemens also provided instructor's materials, including an instruction manual and programming text, as seen in Figure 5. 


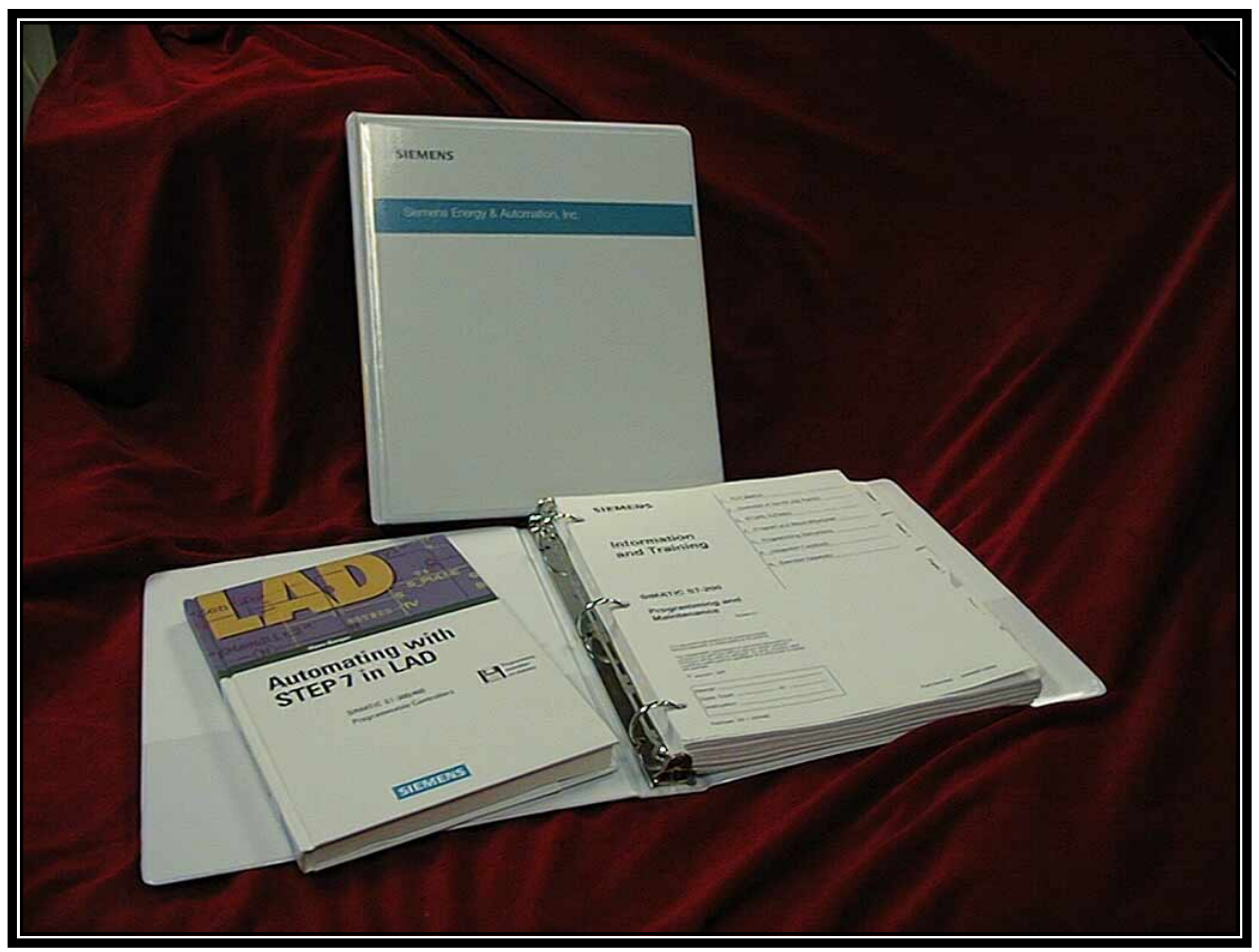

FIGURE 5 Siemens Corporation Simatic S7-200 - Programming \& Maintenance Manuals

- Basics of AC Motors \& Basics of AC Variable Frequency Drives

Although not as complex as the PLC, Variable Frequency Drives (VFD) (sometimes called Adjustable Frequency Drives (AFD)) were the next logical controls device to be taught. As you will recall the course started with "input" devices and progresses to the computer (PLC) that these input devices were connected to. It was now time to complete the loop by associating a complex output device with the computer, such as a variable frequency drive. A simple ICS system device diagram is shown in Figure 6 for clarity.

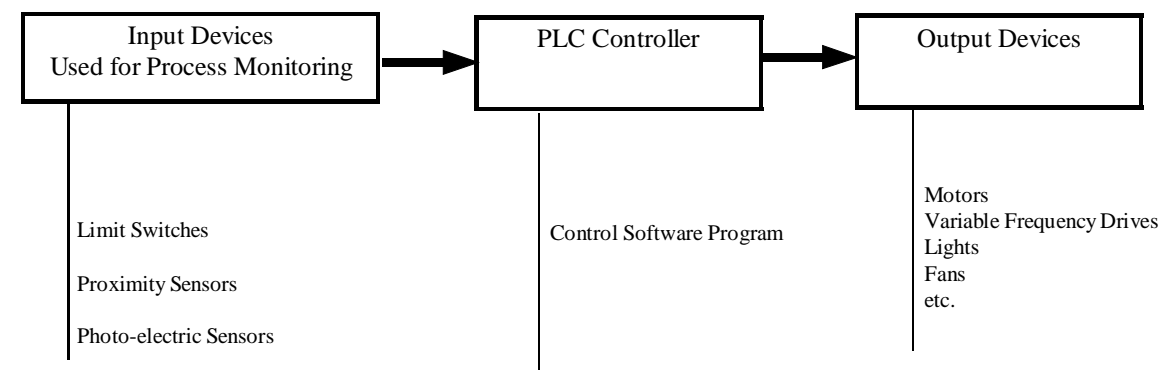

FIGURE 6 Typical ICS Control System

Proceedings of the 2001 American Society for Engineering Education Annual Conference \& Exposition Copyright @ 2001, American Society for Engineering Education 
The VFD is actually a small motor controller that controls the state or condition of various types of motors i.e. AC, DC, etc., and can be considered an "output" of the PLC controller itself. These controllers will require students to acquire knowledge of their hardware as well as the software needed to make them operate. The example curriculum developed in this program utilizes a very small VFD, the Siemens MicroMaster series.

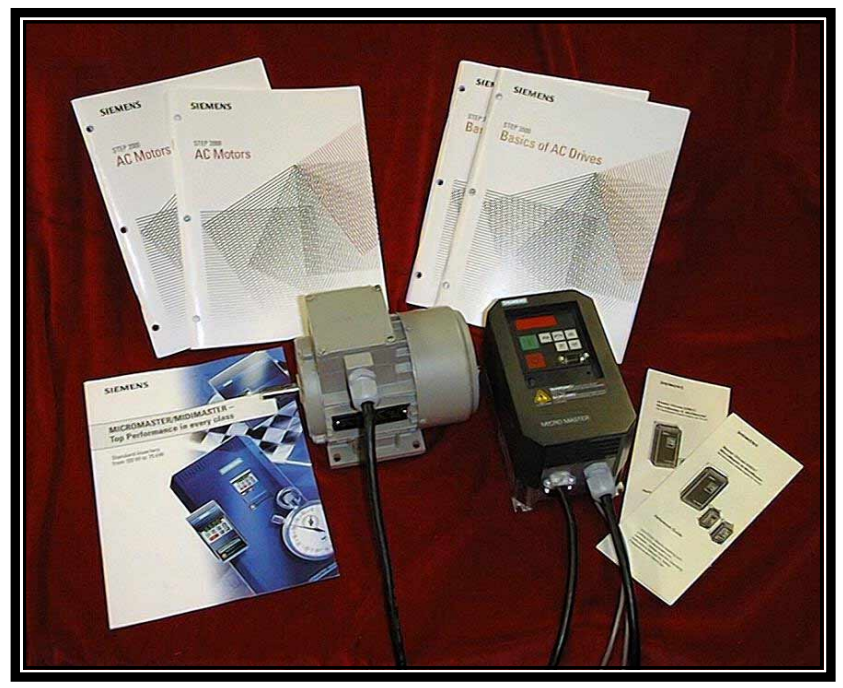

FIGURE 7 Siemens Corporation Step 2000 - Basics of AC Motors and Basics of AC Drives

Siemens Corporation provided a number of interesting materials, including several hundred 100+ page paperback-book learning tools such as Basics of AC Motors, and Basics of AC Drives. Such Variable Frequency Drives and associated text materials are shown in Figure 7.

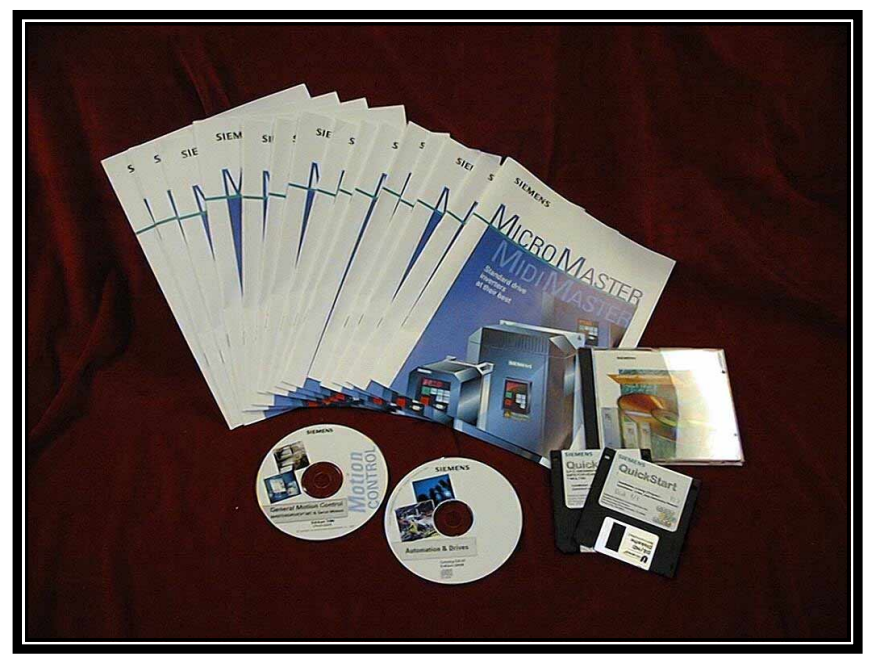

FIGURE 8 Siemens Corporation Variable Frequency Drive Specifications with supporting CD ROM Discs 
To further assist the course developer, Siemens provided extensive materials on VFD specifications and other related information such as educational PowerPoint presentations on CDs as shown in Figure 8.

The course presented above was given as a pilot Lecture-Lab course in the Fall quarter of 1999. The course ran for 10 weeks at 3 hours per week, and was titled: Introduction to Industrial Control Systems in Automation I. This new teaching venue proved to be very successful. As the saying goes, "the proof of the pudding is in the eating". Informal course evaluations were completed by participating students, the positive results of which are provided at the end of this paper. Keep in mind that the facilities used for this experimental lab were limited in size and thus limited to the number of students that were allowed to participate.

\section{DESIGNING A SECOND INDUSTRIAL CONTROL SYSTEMS COURSE}

Following the administration of the first course described above, additional equipment donations to the School of Engineering Technology required that a second more advanced ICS course be developed. The following is a brief description of this second course and the participation and influence that industrial equipment donors have had in its development.

\section{Industrial Control Systems in Automation II}

A second industrial control systems course, Introduction to Industrial Control Systems in Automation II was developed around additional state-of-the-art equipment donated to this program by the Cutler-Hammer Corporation. Cutler-Hammer specializes in a somewhat different approach to industrial control. Their specialty controller is PC based. This particular control system is not a stand-alone, but works in concert with a personal computer under the Windows NT operating environment. A network bus emanates from a special hardware "scanner" card housed in the PC itself. The network bus can have various "smart" devices connected to it. Each device reports directly back to the scanner card via this bus, which is the actual ICS controller.

\section{INDUSTRY INFLUENCE}

\section{Order of Course Material Presentation}

As with the first ICS course developed, industrial advisors were consulted as to the topical order that would be most beneficial. As a result of their feedback and this author's input, the following order of topics was established:

\section{Understanding the Basic Input and Output Devices}

- Limit switches

- Proximity Sensors

- Photo-electric Sensors

Proceedings of the 2001 American Society for Engineering Education Annual Conference \& Exposition Copyright () 2001, American Society for Engineering Education 
- Relays \& Contactors

\section{Networking Protocols \& DeviceNet Training}

- Basics of DeviceNet

- DeviceNet Products

- Physical Media

- Building a DeviceNet System

- Network Communications

- Introduction to NetView \& Device Communications

- PC Based Controls \& NetSolver

- Device Installation \& Planning

- In addition to these topics, students were required to perform weekly design applications

This author relied heavily on the expertise of representatives from Cutler-Hammer to develop the above topics. These representatives have had years of experience in the application and instruction of their products and are in a unique position to know just what material needs to be presented. Cutler-Hammer also graciously donated network equipment and associated training manuals for this course. Examples of these items can be seen in Figure 9. In addition to providing equipment, Cutler-Hammer provided manpower to assist in the course-design and setup of their equipment

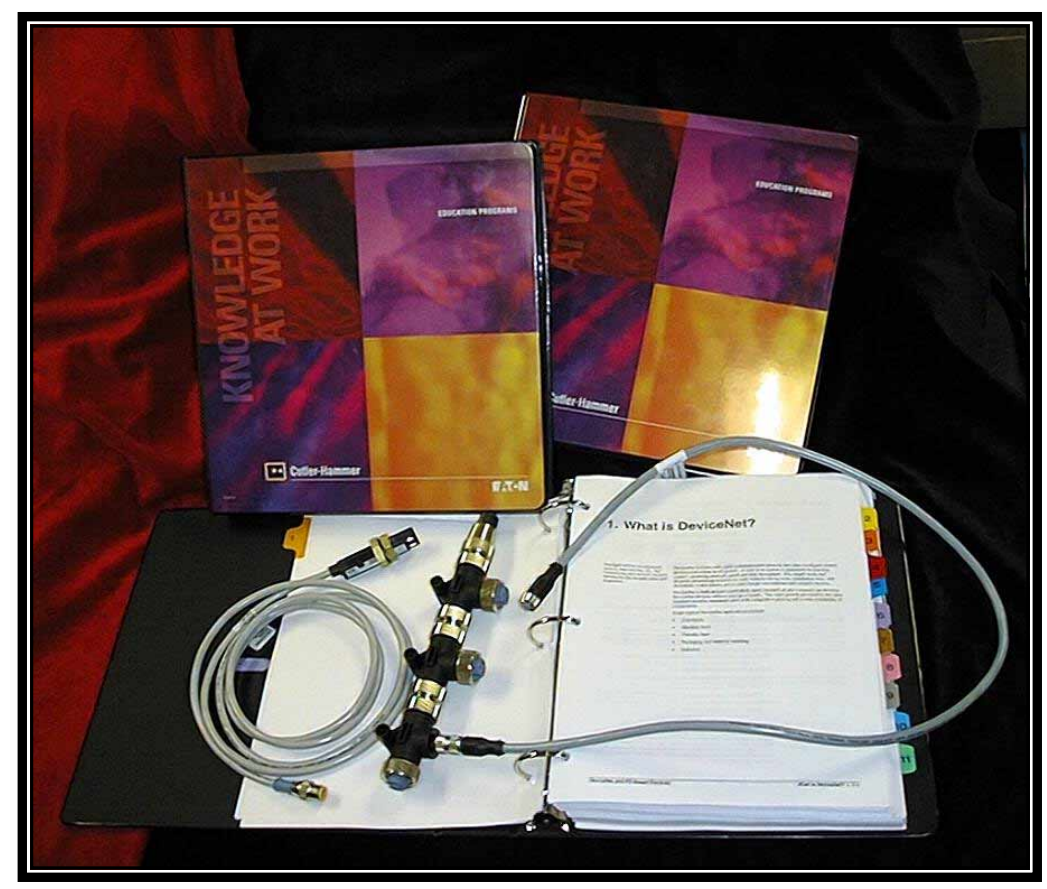

FIGURE 9 Cutler-Hammer Professional DeviceNet Training Manuals and Network Hardware

Proceedings of the 2001 American Society for Engineering Education Annual Conference \& Exposition Copyright (C) 2001, American Society for Engineering Education 


\section{Understanding Basic Input and Output Devices}

As with the first ICS course, controller input devices were the first devices to be taught.

However, these devices are somewhat different in nature than the ones previously described.

Unlike their first-course counterparts, Cutler-Hammer input devices are "programmable". (Keep in mind that devices on a DeviceNet Network are "smart devices" and are programmable to one degree or another.)

\section{Network Protocols and DeviceNet Training}

Each of these topics is explained in detail in the donor supplied manuals shown in Figure 9. In addition to utilizing this industrial equipment and literature, many educational tools were used including compact discs and PowerPoint presentations on the subjects covered in the teaching manual. Other sales/marketing materials were provided on CDs which allowed students to gain additional perspective of the ICS market. Samples of these materials are shown in Figure 10.

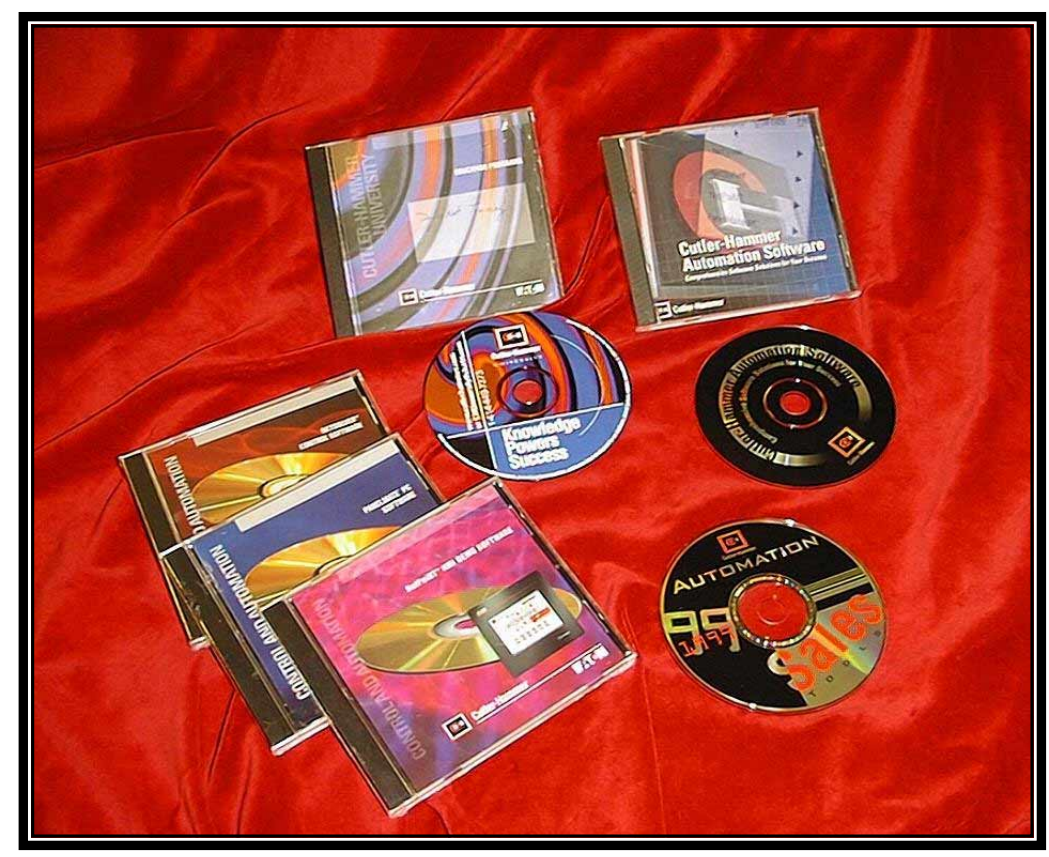

FIGURE 10 Cutler-Hammer DeviceNet Configuration Software and Assorted Supporting CD ROM Discs

\section{Summary}

As can be seen here, industrial influenced curriculum can be very beneficial to all involved. Students benefit through an introduction and direct access to hands-on applied knowledge of "real-world" devices. The educational institution benefits by having established a relationship with industry that will span many years of continued support. And finally, the donor benefits by having created potential business in the form of future post-student purchasing potential. This is

Proceedings of the 2001 American Society for Engineering Education Annual Conference \& Exposition Copyright (C) 2001, American Society for Engineering Education 
truly a win-win-win situation for all concerned and a great way to produce quality industrially influenced curriculum.

\title{
STUDENT EVALUATION COMMENTS
}

\author{
SAMPLE STUdEnt COURSE Evaluation COMMENTS \\ INDUSTRIAL CONTROL SYSTEMS IN AUTOMATION I \\ FALL QUARTER - 1999
}

\section{STUDENT \#1}

"The idea that we can physically see and use the knowledge that we've learned in class... The hands-on approach helps us learn concepts easier....We get to try to answer questions or problems that we may be faced with in a real work environment. We also learn how to work as a team and not just as individuals. This will also help us when we get out and work in our fields ..."

Carlos Tejeda, Class of 2001, EET

Northeastern University, School of Engineering Technology

\section{STUDENT \#2}

"We learned many different control systems and real world applications where we can relate.. As I aim for the industrial field, this class is most definitely the most valuable to me.."

Harold Marzouka, Class of 2000, EET

Northeastern University, School of Engineering Technology

\section{STUDENT \#3}

"What I liked best about the course was the hands-on stress free environment. I also like how we were given the chance to design projects on our own and then create them..I think this course holds value for not only EET students, but all technology students..."

Brian La Croix, Class of 2001, EET

Northeastern University, School of Engineering Technology

\section{STUDENT \#4}

"This course was great fun. It was fun for a change to have a course that focused more on hands-on applications rather than all lectures..."

Nick Armata, Class of 2001, EET

Northeastern University, School of Engineering Technology

\section{STUDENT \#5}

"I enjoyed working, not only in groups, but as a team to complete the projects that were assigned..This course is entirely different from any other course I have taken as an EET student. If I had not taken this course, I would probably graduate knowing very little about industrial control systems, and they are so widely used in industry today..."

Robert Bennett, Class of 2001, EET

Northeastern University, School of Engineering Technology

Proceedings of the 2001 American Society for Engineering Education Annual Conference \& Exposition

Copyright (c) 2001, American Society for Engineering Education 


\section{Bibliography}

1. Tapper, Jerome, "Creating Industrial Partnered Curriculum, A Work in Progress," Proceedings of CIEC, Presented February, 2001, SanDiego, CA, Session ETD 345

2. Tapper, Jerome, "Building Industry Partnerships by Enticing Industry to Work for You," Proceedings of A.S.E.E., Presented June, 2000, St. Louis, MO, Session 2647

3. Tapper, Jerome, "Building Industry Partnerships, The Ket to Creating State of the Art Laboratories,"

Proceedings of CIEC, Presented February, 2000, Orlando, FL, Session CIP/ETD 345

\section{JEROME TAPPER}

Mr. Tapper received a Bachelor of Science Degree in Electrical Engineering in 1970 and a Master of Science Degree in Information Systems in 1998, both from Northeastern University. He is a Registered Professional Engineer in the Commonwealth of Massachusetts with over twenty years of industrial experience in the areas of process control, industrial automation design, circuit design, product development and project management. Mr. Tapper is the author of Electronics for Engineering Technology, a tool-kit based text for electrical engineering technology students. He currently is an Associate Academic Specialist in the area of Electrical Engineering Technology in the School of Engineering Technology at Northeastern University in Boston, Massachusetts. 